\title{
A Note on Spelling and Translations
}

In the text, Nahuatl words are spelled without diacritics to mark glottal stops and vowel lengths, a common convention in scholarly literature. I am using the conventional spelling "Moteuczoma" for the rulers' name, and the spelling adopted by Moteuczoma II's legitimate children, "Moctezoma," when referring to his descendants.

All translations from Spanish are mine, unless a published English translation is cited. All translations from Nahuatl are from the English or Spanish of the cited text, unless my translation is noted. 


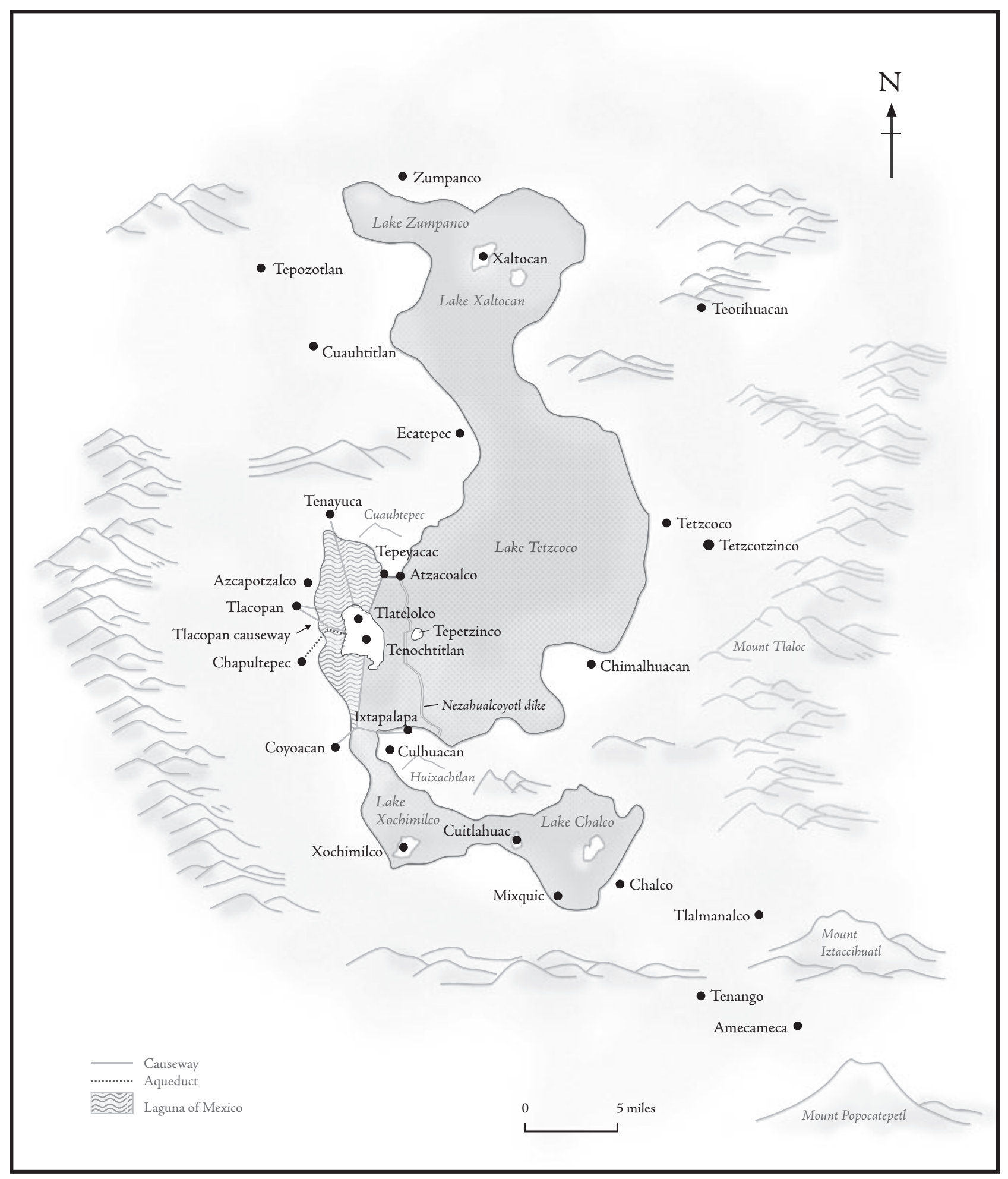

Figure I.I. Map of the Valley of Mexico, by Olga Vanegas. 